\title{
LAS APARICIONES DE LA VIRGEN MARÍA Rafael Mauricio Méndez
}

Santafé de Bogotá. Intermedio Editores-Círculo de Lectores, 262 páginas. 1996.

El libro de Mauricio Méndez, es una suerte de florilegio mariano: una colección de treinta y nueve relatos y leyendas sobre apariciones de virgenes, pero sin ningún sustento teórico - por lo menos en forma expresa. No hace ni apología ni crítica religiosa; es más, ni introducción o presentación ofrece. No es un libro académico, pero deja dos sensaciones: la primera es que permite analizar, clasificar y ordenar con absoluta libertad el conjunto de los relatos. Algo así como si el autor colocara al lector ante un ventanal a observar llanamente lo que quiera; sin sugerir qué mirar y sin indicar en qué punto del horizonte o del paisaje detenerse. La segunda, corolario de la anterior, es lo grata que resulta la lectura de las leyendas. El estilo las asemeja a ciertas versiones popula- res, aunque parecen ser las oficiales de la iglesia. Y, al estar escritas de manera agradable dejan la sensación de haber trabajado en campo, en un lugar ubicuo de América Latina, frente a un ramillete de versiones veredales de una misma aparición.

Con las ausencias académicas anunciadas, y por supuesto sin ningún tipo de conclusiones, este libro tiene en cambio, algo de lo que carecen los libros y muchos de los artículos especializados en el tema: las versiones completas de los mitos o leyendas que utilizan en sus análisis, los cuales de principio a fin son su materia prima. Por tal razón, este libro es un insumo, buena materia prima, para quienes se interesan en el estudio comparativo de los santos y vírgenes desde una perspectiva 
antropológica, por varias razones: la primera es que sugiere la imp ortancia de valorar las versiones de la gente - como una fuente de información importante para las investigaciones - sobre lo que ellas consideran el "real" o "verdadero" origen de la virgen, por encima de las versiones europeas $\mathrm{u}$ oficiales de la Iglesia. La sustitución de los relatos europeos por los propios, es frecuente entre los pobladores de una región; pero también existen quienes les restan valor creyéndolos leyenda o invención y no historia.

La segunda es que los treinta y nueve relatos se pueden organizar; son susceptibles de clasificación por lo menos en siete órdenes (paraje, país, forma teofánica, estructura mítica, sujeto religioso, tipo y característica de la aparición). La tercera es que al presentar relatos de vírgenes representativas a nivel nacional (Guadalupe, Caridad del Cobre, Copacabana, Chiquinquirá y Fátima, Caacupé, etc.), la compilación ofrece un panorama que brinda la posibilidad de construir hipótesis complejas y posibilita la generalización y especificación según el alcance del estudio que se quiera plantear.

La cuarta es que por ser relatos de casos de apariciones sucedidas en dieciséis paises - tres europeos (España, Francia y Portugal), once latinoamericanos (Uruguay, Argentina, Perú y Costa Rica entre otros), dos caribeños (República Dominicana y
Cuba)y, dos norteamericanos (Estados Unidos y Canadá) - aporta datos significativos del orden nacional, regional y local. Y, la quinta y última, es que la información consignada da cuenta de la importancia e impulsa a continuar con los trabajos sobre reelaboraciones étnicas y nacionales de vírgenes y santos en América Latina.

El libro en mención está pensado para un lector general sin ninguna pretensión científica, académica o literaria, pero sí editorial. Está bien hecho, con buen diseño. Lo acompaña una iconografía seleccionada con criterio: óleos de Zurbarán, Da Vinci, Reni y da Messina entre otros.

Es un libro que se debe leer acompañado de otros textos, tanto para los especialistas en el tema como - con mayor razón - para los estudiosos. Sugiero el artículo " $\mathrm{El}$ aparicionismo mariano" de Alicia Barabas (1995). Al leerlo se dará cuenta de que el libro de Méndez, aunque presenta treinta y nueve casos de apariciones de vírgenes, no es un tratado sobre todas "las apariciones de la virgen María”-, como lo sugiere su título. Mucho menos lo es de la complejidad de variaciones existentes de los relatos de aparición de una misma virgen. El aparicionismo mariano, como denominó Barabas al fenómeno, es bastante complejo y representa más de cuarenta mil casos registrados en el mundo. 
Si nos atenemos a esa cifra, cualquier noción de representatividad se pone en duda; pero si uno se detiene a clasificar sus contenidos y a estu. diarlos con cuidado, el trabajo de Mauricio Méndez sí lo puede ser. Por un lado, trae ejemplos que sugieren que no todas las leyendas son de apariciones; no pocas podrian ser entendidas como remanecimientos (léase el artículo de Zambrano en este mismo volumen), algunas como hallazgos y otras como sueños. Es decir, que incluso el libro brinda elementos para discutir con mayor profundidad los límites y posibilidades de la noción de "aparición" y la complejidad empírica del fenómeno.

$Y$, por otro lado, aunque no presenta sino el caso de la virgen de Chinquinquirá de Colombia, tiene treinta y ocho de otros lugares y provincias latinoamericanas. Locual como ya se señaló, en parte es una opción comparativa para quienes estudian dicho fenómeno en localidades (la Dolorosa en Medellín) o regiones (las remanecidas del Macizo Colombiano). Para suplir la carencia de información sobre Colombia, se sugiere el libro de Emma Forero (1988) - similar aunque sin el detalle de los relatos-, que incluye datos generales de casi una centena de vírgenes colombianas, desde la perspectiva de los santuarios.

Las apariciones de la virgen Maria, da cuenta de las múltiples manifestaciones de las apariciones: en cristales, rocas o aguas santas, en Luján, Copacabana o Caacupé. De sus sentimientos - amargura o caridad-, de sus apodos - la tirana, la guaricha y la zamarrilla-, y hasta de milagros curiosos como la del Almuerzo en España. También da cuenta de que se aparecen no sólo a campesinas y campesinos pobres y púberes y a minusválidos como lo han señalado especialistas como Eliade, sino también a vengadores, ladrones, conversos y soldados.

En definitiva, el lector no puede esperar una obra como la trilogía mariana de Félix Báez-Jorge (1994) o el estudio histórico cultural de una santa como el de Luis Millones (1993), o el detalle y minucia en el libro de Olga Portuondo (1995).

El libro de Rafael Mauricio Méndez, puede ser considerado un texto de fuentes marianas. Da consistencia a la pregunta acerca del papel que juegan las hierofanías y teofanías en la construcción de colectividades religiosas y seculares en nuestro continente. Materiales como este son estimulantes porque suscitan muchas preguntas que lamentablemente no se pueden cubrir en la reseña.

\section{BIBLIOGRAFÍA}

\section{BAEZ-JORGE, Félix}

1994 La parentela de María. Cultos marianos, sincretismo e 
identidades nacionales en América Latina. Biblioteca Universidad Veracruzana. México.

BARABAS, Alicia

1995 El aparicionismo en América Latina. En: Laldentidad: Imaginación, recuerdos yolvido.s. Universidad Nacional Autónoma de México. pp. $29-40$.

FORERO, Emma

1988 Los lugares de María. Emma Forero Editora. Bogotá.
AILLONES, Luis .

993 Una parlecita del cielo. La vida de Santa Rosa de Lima. Editorial Horizonte. Lima.

PORTUONDO, OIga

1995 La virgen de la Caridad del Cobre. Símbolo de cubanía. Editorial Oriente. Santiago de Cuba.

Carlos Vladimir Zambrano

Instituto Colombiano de Antropologia 